\title{
Dedication
}

\section{Dedicated to Professor Dr. Rainer K. Silbereisen}

It is with great pleasure that we dedicate the inauguaral issue of the International Journal of Developmental Science (IJDS) to Rainer K. Silbereisen. This issue includes essays by some of the most renowned international developmental scientist and provides an outstanding account of their ideas and future endeavors concerning their work in developmental science. We are convinced that Rainer K. Silbereisen will - even beyond his official retirement - continue to promote the ideas and principles of developmental science as active as throughout his entire career and, as a consequence, will continue to encourage all of us to think interdisciplinary and broadly in the conceptualization of ourresearch questions and interpretation of our results. In our view, no one else in Europe - and particularly in Germany - has been so vocal and dedicated about promoting the ideas concerning developmental science and their implication for research and practice. Rainer is not only one of the leading developmental scientist in Germany who has demonstrated through his work for nearly four decades the exceptional value of an interdisciplinary approach to the advance of research in developmental science, he is also the founding director of the first Center for Applied Developmental Science in Germany, which general aim is to generate and communicate knowledge concerning psychosocial development across the life span leading to effective preventive and interventive programs.

The publication date of this issue falls in line with Rainer's official parting from his university duties. However we know from our personal experience with Rainer - but also from following his professional career and dedication to science - that we can count on his continued support and effort to keep the spirit of developmental science in research and applied work alive!

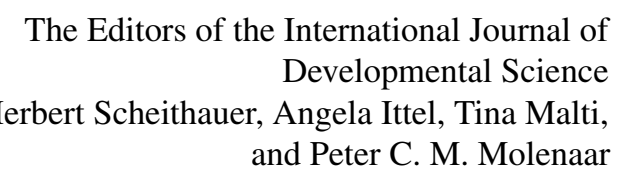

